REPLY

W hile appreciating the concern of Lt Col PJ Vincent for the Ambulance Assistants and his sentimental call for their remustering into the trade of Nursing Assistants, I would like to restrict my comments to my study which was confined to the para-medical and auxiliary staff of AMC in their present jobs. It was not directed towards finding out the medical skills of the auxiliary staff like the Ambulance Assistants whose medical skill is knowingly limited to giving universal first aid. My endeavour was to find out the following in general:-

- Why do people join Army Medical Corps.
- Why do people continue in Army Medical Corps.

- What are the motivating and hygienic factors.

- What do they like and dislike the most in service.

It is presumed that the above information if available may be utilised to harness the human resources in AMC. There may be many areas which the readers may feel that may require change. That is how we grow.

\section{Lt Col TOMMY VARGHESE}

Commanding officer, Military Hospital, Panaji, Goa.

\title{
PULSE DEXAMETHASONE THERAPY IN SYSTEMIC SCLEROSIS
}

\section{Dear Editor,}

Qystemic Sclerosis is a multisystem disorder characterised by the Sassociation of vascular abnormalities, connective tissue sclerosis and atrophy and autoimmune changes [1]. No therapy is known to alter the course of the disease. Hence the need to discover newer and better treatment schedules. We describe the successful management of a case of diffuse cutaneous systemic sclerosis with pulse dexamethasone therapy.

A 28 year old presented to our Centre with insidious onset gradualiy progressive tight and hard skin of the face, trunk and limbs for ten years; and progressive dyspnoea on exertion for three years. There was no cough, hemoptysis, dysphagia or Raynauds phenomenon. Examination revealed mild hypertension, hard bound skin over the face, neck, anterior chest wall, both arms, forearms, proximal lower limbs, gluteal region and upper back. There were no digital scars, sclerodactyly, telangiectasias, or cutaneous discoioration. Hair, nails, genitalia and muscosae were normal. Skin biopsy from shoulder and forearm confirmed scleroderma. ANA was positive and Pulmonary Function Tests (PFT) revealed restrictive lung defect. RA factor, LE Cell phenomenon, Barium meal, 24 hours urinary protein, Echocardiography, USG abdomen, radio-isotope renogram, funduscopy, Serum calcium, X-ray chest, VDRL, ELISA for HIV and other serum biochemical parameters were normal.

He was given four pulses of dexamethasone, each pulse consisting of $100 \mathrm{mg}$ dexamethasone dissolved in $500 \mathrm{ml} 5 \%$ Dextrose infused intravenously over 3-4 hours, for three consecutive days every month. After four pulses, dyspnoea had improved and the skin could be pinched up from the involved areas. Serial PFT revealed improvement, with increase in FVC, FEV 1, MVV, FIV 1 and FIVC (Table 1). The patient had no side effects during therapy except for hiccups on the transfusion days.

Prednisolone exerts an immunosuppressant effect and its use is indicated in inflammatory, immunologically active Systemic Sclerosis [2]. Pulse steroids entail intravenous infusion of suprapharmacological doses over a short time, and are aimed at decreasing the need of long term use of glucocorticoids resulting in fewer long term side effects [3]. Its use in Systemic Sclerosis has been reported recently [4]. Overall improvement was seen in all cases and reversal in one case, following 4-20 pulses of dexamethasone. Malaise and posterior subcapsular cataract have been reported as side effects. PFT can be abnormal even when chest radiology shows no abnormality [5] as was in our case.

Pulse dexamethasone therapy is, therefore, an effective, safe and alternative therapeutic option for the treatment of Systemic Sclerosis.

TABLE 1

Serial PFT

\begin{tabular}{lcrr}
\hline & $\begin{array}{c}\text { Pre } \\
\text { Treatment }\end{array}$ & $\begin{array}{c}\text { After } \\
\text { 2 pulses }\end{array}$ & $\begin{array}{c}\text { After } \\
\text { 4 pulses }\end{array}$ \\
\hline FVC (Ltr) & 2.31 & 2.94 & 4.62 \\
FEV1 (Ltr) & 2.31 & 2.85 & 3.84 \\
FIVC (Ltr) & 2.25 & 2.85 & 4.35 \\
FIV1 (Ltr) & 2.21 & 2.84 & 3.84 \\
MVV (Ltr/min) & 107.70 & 141.40 & 177.00 \\
\hline
\end{tabular}

Sqn Ldr SANJIV GROVER *, Wg Cdr GURCHARAN SINGH + , Lt Col KEDARNATH DASH ${ }^{*}$.

"Graded Specialist, ${ }^{+"}$ Classified Specialist, Department of Dermatology, Command Hospital Air Force, Bangalore 560007.

\section{REFERENCES}

1. Rowell NR, Goodfield MJD. The Connective Tissue Diseases (Systemic Sclerosis). In: Champion RH, Burton JL, Ebling FJG,eds. Textbook of Dermatology. 5th edition. Oxford: Blackwell Scientific Publications. 1992:2241-66.

2. Haustein UF. Current status and trends in treatment of scleroderma. Hautarzt. 1992;43:409-16.

3. Editorial. The big shot. Lancet 1977;309:633-4.

4. Pasricha JS, Raman M, Shah S. Reversal of systemic sclerosis with dexamethasone pulses. Ind J Dermatol Venereol Leprol 1990;56:440-2.

5. Catterall $M_{r}$ Rowel NR. Respiratory function in progressive systemic sclerosis. Thorax 1963;18:10-15.

\section{ERYTHEMA MULTIFORME DUE TO CARBAMAZEPINE}

Dear Editor,

Qkin eruptions occur in about $3 \%$ of patients receiving carSbamazepine and include erythematous, morbilliform, urticarial or purpuric rashes. Toxic epidermal necrolysis and exfoliative dermatitis are well recognised. Eczema, photosensitivity, an LE like syndrome, dermatomyositis, pustular reactions and erythema multiforme are very rare [1]. A case of erythema multiforme due to carbamazepine is reported because of its rarity.

A 35 years old married, Hindu male was hospitalised on 28 Feb 97 for acute onset abnormal behaviour. Physical examination was 
normal. Mental status examination revealed poor self care, hyperactivity, vacant smiling, excessive talking, grandiose ideas which were not very prominent, mildly elated affect and insomnia in a clear sensorium with impaired insight. Investigations including hemogram, urinalysis, LFT, SGOT, SGPT, Blood sugar (fasting and post-prandial), blood urea, serum creatinine, VDRL, skull radiograph and funduscopy were within normal limits. With a diagnosis of unspecified psychosis he was treated with Tab Trifluoperazine (5mg) 1 TDS. Tab Carbamazepine (200 mg) BD was added wef 14 Mar 97 and increased to 1 TDS wef 20 Mar 97. Patient's mental status gradually stabilised. On 13 April 97 onwards he developed successive crops of multiple erythematous rashes all over the body associated with superficial ulcerated lesions in oral cavity, lips and glans penis along with fever and burning sensation all over the body.

On examination temperature was $103.8^{\circ} \mathrm{F}$ and pulse $114 / \mathrm{min}$. Systemic exam was normal. Dermatological exam showed numerous, discrete, erythematous, maculopapular lesions with target lesions in between and central cyanosis, symmetrically distributed all over the body including trunk, extremities, palms and soles.

Multiple superficial ulcerated lesions in buccal mucosa, lips and glans penis were also present. Repeat hemogram, urinalysis, Xray chest PA view and ELISA for HIV were within normal limits. All medications were stopped. He was treated with oral and parenteral steroids, antibiotics and other supportive measures and gradually recovered over the next four weeks. Thereafter he was stabilised with Tab Trifluoperazine.

Erythema multiforme is more commonly precipitated by various infections and therefore many instances may have been wrongly blamed on drugs. In the present case, however, no infection was present. Clinically macular, papular or urticarial lesions, as well as the classical iris or "target lesions" sometimes with central vesicles, bullae or purpura, are distributed preferentially on the distal extremities but may involve the palms or trunks as seen in our patient. Involvement of conjunctival, comeal, iris, buccal, labjal and genital mucous membranes occurs in the Stevens-Johnson syndrome [1].

In a prospective study of erythema multiforme, only $10 \%$ were drug related [2], but re-exposure has confirmed a drug cause in many instances. Since re-exposure to a drug suspected of causing the reaction has resulted in fatality, it should not be carried out for diagnostic purpose [1], and therefore was not attempted in our patient.

Studies on carbamazepine in psychiatry have mostly reported its efficacy in different mental disorders, but its adverse effects in psychiatric patients have found little attention [3]. The belief that adverse effects in psychiatric patients are as frequent as in neurological patients is not true [3]. The $10-15 \%$ incidence of skin rashes reported in psychiatric patients on carbamazepine $[4,5]$ is much higher than the $3 \%$ incidence in neurological patient $[1,3]$.

Similarly the observation about the rarity of erythema multiforme in neurological patients while on carbamazepine therapy may not hold good for psychiatric patients.

Regardless of its frequency, the occurrence of a potentially fatal side-effect like erythema multiforme highlights the fact that carbamazepine treatment carries potential risks which should be weighed against its benefits before initiating therapy especially in psychiatric patients.

Col P RAMADASAN *, Lt Col S CHAUdHURY ${ }^{+}$, Maj TR JOHN", Maj R GULATI

"Senior Adviser (Derm \& Venereology), ${ }^{+}$Classified Specialist (Psychiatry), "Graded Specialist (Psychiatry), " Graded Specialist (Derm \& Venereology), Command Hospital (Northern Command), C/0 56 APO.

\section{REFERENCES}

1. Breatnach SM. Drug reactions. In: Champion RH. Burton JL. Ebling FJG, editors. Textbook of Dermatology, 5th edition. Oxford:Blackwell Scientific Publication 1992;2961-3036.

2. Huff JC, Weston WL. Tonnessen MC. Erythema multiforme: a critical review of characteristics, diagnostic criteria and causes. J Am Acad Dermatol 1982;8:763-5.

3. Jain R. Stevens-Johnson syndrome in a schizophrenic patient treated with carbamazepine. Indian J Psychiat 1993:35:139-40.

4. Elphick M, Lyons F, Cowen PJ. Low tolerability of carbamazepine in psychiatric patients may restrict its clinical usefulness. J Psychopharmacol 1988:2:1-4.

5. Kaplan HI, Sadock BJ. Synopsis of Psychiatry, 8 th edition. New Delhi. B.I. Waverly Pvt Ltd. 1988;1008-14.

\section{MEHTA'S PERIOSTEAL ELEVATOR-A NEW SURGICAL INSTRUMENT}

Dear Editor,

T The usual instruments employed to raise the mucoperiosteum in nasal and septal surgery are the Freer's and Joseph's periosteal elevators. Surgical procedures in this highly vascularised area result in haemorrhage which tends to obscure the plane of dissection and requires constant suctioning to clear the operative field.

To obviate the need for dual instrumentation in narrow confines of the nose end the actions of periosteal elevation and suction have been combined into one instrument (Fig 1).

The instrument is made of stainless steel. It consists of a hollow tube one end of which is bevelled to serve the purpose of an elevator The other end is knob shaped to which a flexible suction tubing can be attached. It has a handle for firm grip and a small opening midway for suction control (Fig 2).

This instrument has very successfully been tried during Septoplasty, rhinoplasty and mastoidectomy. It can very comfortably be used for palatal surgeries, thyroid cartilage surgeries and in any situation where profuse haemorrhage is expected during periostal elevation.

Lt Col AK MEHTA

Classified Specialist ENT, President SMB, C/o Military Hospital, Bhopal. 